\section{HSE}

Historia Social y de la Educación

Social and Education History
Hipatia Press

www.hipatiapress.com

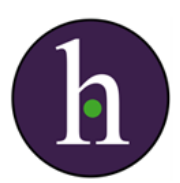

Instructions for authors, subscriptions and further details:

http://hse.hipatiapress.com

\title{
A philosophical examination of social justice and child poverty
}

Raquel Moreira ${ }^{1}$

1) Universidade Federal de São Carlos (Brasil).

Date of publication: October $23^{\text {rd }}, 2016$

Edition period: October 2016-February 2017

To cite this article: Moreira, R. (2016). A philosophical examination of social justice and child poverty [Review of the book]. Social and Education History 5(3), 297-299 doi:10.17583/hse.2016.2295

To link this article: http://dx.doi.org/10.17583/hse.2016.2295

\section{PLEASE SCROLL DOWN FOR ARTICLE}

The terms and conditions of use are related to the Open Journal System and to Creative Commons Attribution License (CC-BY). 
HSE - Social and Education History Vol.5 No. 3 October 2016 pp. 297-311

\section{Reviews (I)}

Schweiger, G., \& Graf, G. (2015). A philosophical examination of social justice and child poverty. Inglaterra: Palgrave Macmillan UK.

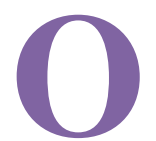

que significa ser pobre? Quais aspectos determinam a pobreza? Quais são os parâmetros para mensurar a pobreza? A pobreza pode determinar a vida de uma pessoa? Quem é responsável por ajudar a mudar as condições de vida dos pobres? A análise da pobreza e da justiça social é a mesma para crianças e adultos? Estas são algumas indagações e reflexões que Gottfried Schweiger e Gunter Graf abordam em "A philosophical examination of social justice and child poverty", para delinear a análise da pobreza infantil enquanto injustiça social.

Schweiger e Graf afirmam que a luta contra a pobreza infantil deve se respaldar em estudos multidisciplinares, combinando investigações críticas do ambiente econômico, social e político em que é produzida e reproduzida, com o modo que as instituições nacionais e internacionais agem para erradicá-la. Ressaltam que a filosofia pode contribuir, principalmente, a partir de aspectos normativos e éticos. Neste sentido, buscando ir além dos apontamentos da falta dos elementos básicos da vida, os autores delimitam o estudo da pobreza infantil no contexto dos países desenvolvidos, com foco numa avaliação moral do problema.

O livro conta com quatro capítulos. No primeiro, os autores traçam uma teoria da justiça social para crianças ancorada na abordagem das capacidades a partir de Amartya Sen e Martha Nussbaum. Destacando os conceitos de funcionamentos e de capacidades como essenciais para se fazer e ser autônomo, entendido como "bem-estar", eles afirmam que os 
funcionamentos são as atividades e os estados que compõem a vida de uma pessoa, garantindo à ela o acesso às capacidades para o "bem-estar", pautando a compreensão de justiça. Todavia, evidenciam a necessidade de um conceito de justiça específico às crianças, uma vez que elas não podem ser responsabilizadas por suas escolhas de vida tal como os adultos. Propõem um conceito normatizado pelos funcionamentos e não pelas capacidades, que deve operar na tensão do presente com o futuro, vislumbrando concomitantemente a criança enquanto criança e enquanto um futuro adulto. Com isto apresentam os conceitos de "bem-estar" e de "bemtornando-se" como categorias normativas, defendendo um limiar de funcionamentos que propiciem a igualdade de oportunidades ao acesso das capacidades necessárias ao "bem-estar".

No segundo capítulo, Schweiger e Graf examinam a pobreza infantil enquanto injustiça social. Respaldados pelos resultados das pesquisas empíricas, demonstram que a pobreza gera desvantagens corrosivas ao afetar negativamente mais de um funcionamento, comprometendo as capacidades para o "bem-estar" e o "bem-tornando-se". Junto a isso, evidenciam a saúde (mental e física), a educação e a inclusão social como funcionamentos férteis para outras funções e capacidades, utilizando-as como base de considerações normativas para mensurar a pobreza infantil.

Delimitado justiça social e pobreza infantil, os autores desenvolvem, no terceiro capítulo, um modelo de responsabilidades, tomando as contribuições de Iris Young e avançando numa proposta que parte dos aspectos de: causalidade, poder, privilégio e interesse. Ademais, distinguem oito grupos potenciais de agentes de justiça: a criança pobre, a família e cuidadores próximos, a comunidade de entorno e os ambientes sociais próximos, o Estado e suas instituições, a comunidade de cidadãos, a economia, a instituição internacional e a comunidade global. Mensurando, ao final, diferentes pesos para cada um, sem, ao mesmo tempo, desconsiderar a ampla responsabilidade de todos.

Compreendendo que o contexto de análise, países desenvolvidos, enviesa as argumentações e conceitos apresentados, os autores elencam, no último capítulo do livro, possíveis modificações para uma expansão da análise a nível mundial, a saber: delimitação dos limiares de funcionamentos a nível universal e redimensionamento das responsabilidades dos agentes de justiça. Encerram argumentando que muitas das defesas apresentadas podem ser mantidas e servir de base para avanços das questões de justiça e de pobreza 


\section{HSE - Social and Education History, 4(2) 299}

infantil a nível mundial, ressaltando, que sua erradicação efetiva só ocorrerá se tratada como um fenômeno global.

Salienta-se nesta obra o caráter propositivo normativo sobre pobreza infantil enquanto injustiça social, proporcionando a compreensão de que nos fazemos nas interações estabelecidas com outras pessoas e com o ambiente em que vivemos, repercutindo no que somos capazes de ser e fazer. Com isso, traz importantes contribuições às ações de erradicação da pobreza infantil e possibilita uma análise crítica acerca dos estudos do tema, oferecendo reflexões e destacando aspectos que precisam ser aprofundados em processo contínuo de investigação.

Raquel Moreira

Universidade Federal de São Carlos (Brasil)

profraquelmoreira@gmail.com 